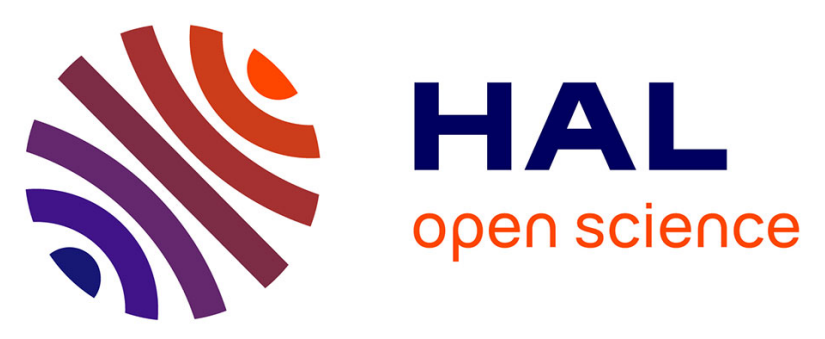

\title{
Liver iron, HFE gene mutations, and hepatocellular carcinoma occurrence in patients with cirrhosis.
}

Pierre Nahon, Angela Sutton, Pierre Rufat, Marianne Ziol, Gabriel Thabut, Pierre-Olivier Schischmanoff, Dominique Vidaud, Nathalie Charnaux, Philippe Couvert, Nathalie Ganne-Carrie, et al.

\section{To cite this version:}

Pierre Nahon, Angela Sutton, Pierre Rufat, Marianne Ziol, Gabriel Thabut, et al.. Liver iron, HFE gene mutations, and hepatocellular carcinoma occurrence in patients with cirrhosis.. Gastroenterology, 2008, 134 (1), pp.102-10. 10.1053/j.gastro.2007.10.038 . inserm-00289290

\section{HAL Id: inserm-00289290 https://www.hal.inserm.fr/inserm-00289290}

Submitted on 20 Jun 2008

HAL is a multi-disciplinary open access archive for the deposit and dissemination of scientific research documents, whether they are published or not. The documents may come from teaching and research institutions in France or abroad, or from public or private research centers.
L'archive ouverte pluridisciplinaire HAL, est destinée au dépôt et à la diffusion de documents scientifiques de niveau recherche, publiés ou non, émanant des établissements d'enseignement et de recherche français ou étrangers, des laboratoires publics ou privés. 
Liver iron, HFE gene mutations and hepatocellular carcinoma occurrence in patients with cirrhosis.

Short title: Iron, HFE and hepatocellular carcinoma

\begin{abstract}
PIERRE NAHON,${ }^{*, \&}$ ANGELA SUTTON, ${ }^{\&, \#}$ PIERRE RUFAT, ${ }^{\mu}$ MARIANNE ZIOL, ${ }^{\alpha, \beta}$ GABRIEL THABUT ${ }^{\gamma}$ PIERRE-OLIVIER SCHISCHMANOFF, ${ }^{\beta, \pi}$ DOMINIQUE VIDAUd,${ }^{x}$ NATHALIE CHARNAUX, ${ }^{\&, \#}$ PHILIPPE COUVERT, ${ }^{*}$ NATHALIE GANNE-CARRIE, ${ }^{*,}$ JEAN-CLAUDE TRINCHET, ${ }^{*, \Delta}$ LILIANE GATTEGNO, ${ }^{\&, \#}$ MICHEL BEAUGRAND. ${ }^{*, \&}$
\end{abstract}

"Service d'Hépato-gastroentérologie, Hôpital Jean Verdier, AP-HP, Bondy, France; ${ }^{\circledR}$ UPRES EA3410, UFR SMBH, Université Paris XIII, Bobigny, France; ${ }^{\#}$ Service de Biochimie, Hôpital Jean Verdier, AP-HP, Bondy, France; " ${ }^{\circ}$ Département MSI, Groupe Hospitalier PitiéSalpêtrière, AP-HP, Paris, France; ${ }^{\alpha}$ Service d'Anatomie Pathologique, Hôpital Jean Verdier, AP-HP, Bondy, France; ${ }^{\beta} U P R E S$ EA3406, UFR SMBH, Université Paris XIII, Bobigny, France; ' Département d'Epidemiologie, Biostatistique et Recherche Clinique, Groupe hospitalier Bichat Claude Bernard, APHP, Paris ; ${ }^{\pi}$ Service de Biochimie, Hôpital Avicenne, AP-HP, Bobigny, France; '^Service de Biochimie, Hôpital Beaujon, AP-HP, Clichy, France; ${ }^{\triangle}$ UPRES EA3409, UFR SMBH, Université Paris XIII, Bobigny, France.

Acknowledgements : The work was supported in part by grants from SNFGE (Société Nationale Française de Gastroentérologie) and Université Paris XIII. The authors are greatful to Pr Sylvie Chevret (Département de Bio-Statistiques, Hôpital Saint-Louis, Paris, France) for her help in statistical analysis.

No conflict of interest exist.

Abbreviations: AFP, $\alpha$-fetoprotein; CHC, chronic hepatitis C; HCC, hepatocellular carcinoma; HCV, hepatitis C virus; ROS, reactive oxygen species; SVR, sustained virological response.

Correspondence: Pierre Nahon, Service d'Hépato-gastroentérologie, Hôpital Jean Verdier, 93140 Bondy, France.

Tel : 33-1-48-02-62-80 Fax : 33-1-48-02-62-02 Email : pierre.nahon@jvr.ap-hop-paris. 


\section{ABSTRACT}

Background and aims: The influence of HFE gene mutations and liver iron overload on hepatocellular carcinoma (HCC) occurrence in patients with cirrhosis is subjected to controversial results. The aim of this work was to clarify this influence in a large cohort of prospectively followed-up cirrhotic patients classified according to the cause of their liver disease. Methods: Three hundred one consecutive cirrhotic patients (162 alcoholic and 139 HCV-infected patients) were included at time of diagnosis of cirrhosis and followed-up. Liver iron overload on initial biopsy according to modified Deugnier's score and C282Y/H63D HFE gene mutations were assessed. Results: In patients with alcoholic cirrhosis (mean iron score $=2.0 \pm 3.0$; mean time of follow-up; $66.1 \pm 45.1$ months), 40 (24.6\%) developed HCC. Thirteen $(8.02 \%)$ were heterozygotes for $\mathrm{C} 282 \mathrm{Y}$ HFE gene mutation and had higher hepatic iron scores $(3.6 \pm 3.8$ vs $1.9 \pm 2.8$, respectively, $\mathrm{p}=0.05)$. In univariate analysis, liver iron as a continuous variable $(\mathrm{HR}, 1.23[1.13-1.34], \mathrm{p}<0.001)$ or in binary coding with an optimal threshold of iron score $\geq 2.0$ (HR, 4.1 [2.1-7.3], $<<0.0001)$ and $\mathrm{C} 282 \mathrm{Y}$ mutation carriage (HR, $2.7[1.2-6.3], p=0.01)$ were risk factors for HCC. In multivariate analysis, liver iron and C282Y mutation carriage remained independent risk factors for HCC. In patients with HCV-

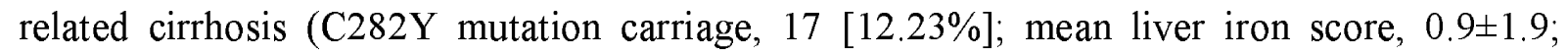
mean time of follow-up, $85.5 \pm 42.1$ months; HCC, 63 [45.32\%] patients), C282Y mutation carriage and liver iron were not associated with HCC occurrence. Conclusions: Liver iron overload and $\mathrm{C} 282 \mathrm{Y}$ mutation are associated with a higher risk of HCC in patients with alcoholic but not HCV-related cirrhosis. 


\section{INTRODUCTION}

As hepatocellular carcinoma (HCC) is increasingly becoming a major cause of death in cirrhotic patients, ${ }^{1}$ periodical ultrasonographic screening is now widely performed as routine. ${ }^{2}$ The search for epidemiological, biological or genetic factors that could help to select patients at higher risk and thus to modulate the indications of screening procedures is necessary. ${ }^{3}$ Moreover, identification of predictive factors could presumably lead to a better understanding of hepatocarcinogenesis and new prevention strategies in these patients. ${ }^{4}$

Among these factors, the influence of liver iron overload and HFE gene mutations has been debated over the past few years. The two missense mutations C282Y and H63D explain most of the cases of haemochromatosis, ${ }^{5}$ a condition characterized by hepatic iron overload and leading to high cancer incidence. ${ }^{6,7}$ Eighty to $100 \%$ of these patients are homozygotes for the $\mathrm{C} 282 \mathrm{Y}$ mutation and about $5 \%$ are compound heterozygotes. ${ }^{5}$ The issue whether patients with other liver diseases heterozygotes for these mutations could develop liver iron overload that could enhance liver injury and carcinogenesis remains unclear.

Liver iron accumulation leads to reactive oxygen species (ROS) formation in the liver, thus causing oxidative stress, liver cell DNA mutations and the development of HCC. ${ }^{8}$ Besides ageing and male gender which are well known risk factors for liver iron accumulation as well as for HCC, seeking for genetic markers of HCC such as HFE gene mutations that could act by increasing hepatic iron overload and thus HCC occurrence is of major interest as it would validate the carcinogenic role of liver iron and suggest preventive measures.

Whether moderate liver iron overload observed in the course of cirrhosis and the HFE mutations carriage could be associated with the risk of $\mathrm{HCC}$ in these patients remains unclear. ${ }^{9}$ Some studies described higher prevalence of the $\mathrm{C} 282 \mathrm{Y}$ mutation in patients with $\mathrm{HCC}$ compared with cirrhotic patients without HCC ${ }^{10,11}$ while other studies displayed a lack of association between this mutation and HCC. ${ }^{12,}{ }^{13}$ Moreover, the influence of the HFE 
mutations on hepatic iron accumulation is also debated. Finally, the influence of liver iron overload on the risk of HCC, requiring prospective cohort studies, has never been clearly shown. Unfortunately, all previous works were case-control studies including small cohorts of cirrhotic patients and mixing various causes of liver diseases, thus limitating the confidence in the different conclusions drawn. Indeed, several limitations are obvious when studying these parameters: the different importance of iron metabolism in hepatocarcinogenesis pathways according to the aetiology of liver disease, the strong correlation between liver iron overload and ageing or male gender leading to methodological bias in multivariate analysis and the weak prevalence of the $\mathrm{C} 282 \mathrm{Y}$ mutation in the studied populations.

To our knowledge, the only prospective study dealing with the influence of liver iron overload in cirrhotic patients was the one by Ganne-Carrie et al. ${ }^{14}$ Conducted in 229 cirrhotic patients before the era of routine HFE gene mutations determination, this work displayed a lack of influence of liver iron overload on survival in patients with HCV-related cirrhosis but a strong influence in alcoholic cirrhotic patients. This study failed to demonstrate an association between liver iron overload and HCC incidence in these patients, possibly due to an insufficient number of patients with alcoholic cirrhosis and a low number of events.

The aim of the present study was therefore to assess on a large cohort of aetiologically defined and prospectively followed-up cirrhotic patients the influence of liver iron overload and HFE gene mutations on the risk of HCC according to the cause of liver disease (alcoholic or HCV-related) and the possible role of HFE gene mutations in this setting. 


\section{PATIENTS AND METHODS}

\section{Patients}

The present study was part of an ongoing prospective study, aiming to assess the rates of HCC development in the course of various liver diseases.

In the present study, we compiled all new patients who were consecutively referred to our liver unit for diagnosis and management of cirrhosis between January 1, 1990 and December 31, 2000, and who fulfilled the following inclusion criteria: 1) biopsy-proven cirrhosis; 2) no infection by the human immunodeficiency virus, or hepatitis B virus; 3) no evidence of HCC at the time of inclusion, as judged by negative ultrasonographic findings and serum $\alpha$-fetoprotein (AFP) less than $50 \mathrm{ng} / \mathrm{mL}$; 4) residence in France 5) Caucasian origin; 6) acceptance of a regular follow-up and periodical HCC screening; and 7) written informed consent for the use of frozen DNA. A total of 301 patients met all these inclusion criteria. All had a known outcome at least until August 31, 2005.

These patients were divided in two distinct cohorts according to aetiology of liver disease. Patients with alcoholic cirrhosis $(n=162)$ were defined as 1$)$ daily alcohol intake $>80$ grams per day and 2) no infection by HCV defined by negative serum HCV antibodies. Patients with HCV-related cirrhosis ( $n=139)$ were defined as 1$)$ daily alcohol intake $<20$ grams per day and 2) chronic infection by HCV defined by positive serum HCV-RNA. In this study, no patients with mixed alcoholic and HCV-related cirrhosis referred in our unit during this period were enrolled $(n=28)$.

For each patient, the date of inclusion was the date of the first liver biopsy showing cirrhosis. Gender, age, presence of ascites or hepatic encephalopathy, serum bilirubin, albumin and prothrombin levels, serum alanine aminotransferase (ALT) activity, serum aspartate aminotransferase (AST) activity, serum gamma glutamyl transferase (GGT) activity, platelet 
count, serum ferritin levels, body mass index (BMI), past history of diabetes were recorded at inclusion. Daily alcohol intake was recorded by interviewing all patients. In patients with HCVrelated cirrhosis, virus genotype was precised.

All patients were prospectively evaluated at least every 6 months by physical examination, liver ultrasonography and serum AFP measurements. When these investigations suggested a possible diagnosis of HCC, computed tomodensitometry and/or magnetic resonance imaging and/or a guided liver biopsy were performed according to the recommendation of the Barcelona Conference. ${ }^{3}$ HCC was diagnosed on either one of the following criteria: histological evidence or convergent demonstration of a focal lesion more than $2 \mathrm{~cm}$ in size and with arterial hypervascularization by two different imaging techniques, or the combination of one imaging technique showing this morphological aspect with a serum AFP level of $400 \mathrm{ng} / \mathrm{mL}$ or more.

The two main end-points were the occurrence of HCC, and the occurrence of death or liver transplantation. Follow-up ended at the date of death or liver transplantation, or at the last recorded visit (or information) within the last 6 months before August 31, 2005, which was set as the final time limit for upgrading the patients' file, using our computerized data-base, departmental certificates for patients who died outside our liver unit or by reaching patients, their relatives or their usual physicians.

In patients with HCV-related cirrhosis, anti-viral treatment and sustained virological response (SVR) were recorded.

\section{DNA Extraction, Amplification and HFE Genotyping.}

DNA samples were prepared from blood $(n=228)$ or frozen liver samples $(n=73$, without any unsuccessful extraction reported). All patients gave written consent for blood sampling and genotyping. The use of left over liver specimens (no longer used for diagnostic purposes) for 
research purposes had been approved by the Comité Consultatif d’Éthique Médicale du Centre Hospitalier Bichat-Beaujon.

For the determination of the Cys282Tyr and His63Asp mutations of the HFE gene, the DNA of each patient was amplified in real-time PCR accordingly with the manufacturer's instructions (Applied Biosystems, Courtaboeuf, France). ${ }^{15}$

\section{Histological Assessment of Hepatic Iron.}

Hepatic iron was assessed on the initial liver biopsy showing cirrhosis. Liver specimens were fixed in formalin and routinely processed. Four- $\mu \mathrm{m}$ thick paraffin embeded liver biopsy sections were stained with the Perls' stain, and examined on a multipipe microscope by two observers unaware of genotypic and clinical data. To semi-quantitatively evaluate hepatic iron deposits, we used the Deugnier's histological hepatic iron score, adapted to cirrhotic samples as described previously (ranging from 0 to 33 ). ${ }^{14}$

\section{Statistical Analysis.}

Qualitative variables were compared using the Fischer exact Chi-2 test or Chi-2 trend test with 1 degree of freedom, while quantitative variables were compared using the non-parametric Wilcoxon test. Pearson correlation coefficient was calculated to measure the relationship between variables. Multivariate analysis (analysis of variance) was also conducted to compare more than two means. The Kaplan-Meier method was used to estimate the occurrence of HCC for each parameter noted at enrolment, death was considered as an outcome in the experiment. The distribution of death and HCC were compared with the Log-rank test. Different thresholds of liver iron scores for the risks of death and HCC occurrence were step by step tested. A significant level below 0.10 was used to select the variables in the Cox's proportional hazards model, using a stepwise backward procedure with a threshold of $\alpha=0.05$. Variables (iron score, 
age, sex) associated with risks of HCC based on knowledge and findings from previous studies were also selected. Statistical analysis used the SAS System Package version 8.02 (SAS Institute, Cary, NC). All reported $P$ values are two-tailed. Associations were first considered statistically significant at a two-tailed $\alpha$ of 0.05 . Bonferroni adjustment was also applied to correct for the number of primary outcomes tested (i.e., for 10 primary outcomes, $\alpha=0.005$ ). All reported $P$ values are not corrected. 


\section{RESULTS}

\section{Baseline characteristics of patients and follow-up}

Clinical and biochemical features of the 301 patients recorded at inclusion are summarized in Table 1 according to the aetiology of cirrhosis. Along with parameters reflecting iron metabolism, parameters estimating the severity of liver disease such as ChildPugh score or known risk factors for HCC occurrence are displayed in this table.

Regarding HFE gene mutations, none of the studied patients were homozygotes for the C282Y mutation, 3 patients with alcoholic cirrhosis were homozygotes for the H63D mutation and 4 patients were compound heterozygotes ( 1 with alcoholic cirrhosis and 3 with HCV-related cirrhosis).

Mean duration of follow-up in patients with alcoholic cirrhosis was $66.5 \pm 44.1$ months. Twelve patients were lost to follow-up during this time. Mean duration of follow-up in patients with HCV-related cirrhosis was $85.5 \pm 42.1$ months. Two patients were lost to followup during this time.

\section{Liver iron in patients with alcoholic cirrhosis}

During follow-up, 40/162 (24.6\%) patients developed HCC (Table 1). According to Kaplan Meier method (Figure 1), the presence of stainable liver iron was associated with the risk of HCC occurrence (first quartile time to occurrence: 54.0 months vs 180.0 months, $H R=3.3[1.6-6.7], \operatorname{LogRank}=0.0006)$. An optimal threshold value $\geq 2$ for liver iron score was found associated with HCC occurrence in this cohort (first quartile time to occurrence: 49.0 months vs 180.0 months, $\mathrm{HR}=4.2$ [2.1-8.5], LogRank<0.0001) (Figure 2). In univariate analysis according to Cox's proportional hazards model, liver iron score was associated with the risk of HCC when considered as a continuous variable $(1.23[1.13-1.34], \mathrm{p}<0.0001)$ or in 
binary coding $(4.1[2.1-7.3], \mathrm{p}<0.0001)$ along with age, male gender, and $\mathrm{C} 282 \mathrm{Y}$ mutation carriage (Table 2). In multivariate analysis taking in account all these parameters, liver iron overload remained an independent risk factor for HCC along with age and C282Y mutation carriage, when considered as a continuous variable $(1.14[1.04-1.25], p=0.003)$ or in binary coding $(2.8[1.4-5.4], \mathrm{p}=0.002)$.

During follow-up, 49/162 $(30.2 \%)$ patients died $(n=45)$ or underwent liver transplantation $(n=4)$ (Table 1). Death was attributable to liver disease in all cases, due to advanced HCC in 19 cases or due to variceal bleeding and/or liver failure in the 30 other cases. An optimal threshold value $\geq 5$ for liver iron score was found associated with death in this cohort (first quartile time of survival: 49.0 months vs 70.0 months, $H R=2.3$ [1.2-4.4], LogRank=0.01).

The amount of daily alcohol intake recorded at inclusion was not significatively correlated with liver iron score $(r=0.15, p=0.07)$ and the risk of HCC occurrence $(r=0.17$, $\mathrm{p}=0.06)$.

Liver iron score when considered as a continuous variable was associated in this cohort with old age, male gender, hyperferritinemia, and $\mathrm{C} 282 \mathrm{Y}$ mutation carriage (Table 3).

\section{Liver iron in patients with $\mathrm{HCV}$-related cirrhosis}

During follow-up, 63/139 (45.3\%) patients developed HCC (Table 1). According to Kaplan Meier method (Figure 1), the presence of stainable liver iron was not associated with the risk of HCC occurrence in this cohort (first quartile time to occurrence: 48.0 months vs 50.0 months, $\mathrm{HR}=0.9$ [0.5-1.7], LogRank=0.9). Conversely to patients with alcoholic cirrhosis, no optimal liver iron cut-off value was found associated with the risk of HCC (Figure 2). In univariate analysis according to Cox's proportional hazards model, liver iron score was not associated with the risk of HCC; only old age, male gender, the absence of anti- 
viral treatment or of SVR were associated with the risk of HCC occurrence in this cohort (Table 2). In multivariate analysis taking in account all these parameters, only anti-viral treatment and male gender remained independent risk factors for $\mathrm{HCC}$.

During follow-up, 28/139 (20.1\%) patients died $(n=24)$ or underwent liver transplantation $(n=4)($ Table 1$)$. Death was attributable to liver disease in all cases, due to advanced HCC in 25 cases or due to variceal bleeding and/or liver failure in the 3 other cases. The presence of stainable liver iron was not associated with the risk of death in this cohort (first quartile time of survival: 48.0 months vs 50.0 months, $H R=0.5$ [0.1-1.5] LogRank=0.2). Conversely to patients with alcoholic cirrhosis, no optimal liver iron cut-off value was found associated with the risk of death.

Eighty/139 (57.5\%) patients underwent curative anti-viral treatment, which led to SVR in 32 of them. Twenty-eight/80 (35\%) treated patients had stainable liver iron. In patients with SVR, 14/32 (43.7\%) had stainable liver iron (median=0 [Q1=0 - Q3=2.5]) vs 14/48 (29.1\%) (median=0 $[\mathrm{Q} 1=0-\mathrm{Q} 3=1])$ in patients without $\mathrm{SVR}(\mathrm{p}=0.1)$.

In the subset of the 59 untreated patients, $14(23.7 \%)$ had stainable liver iron. This stainable liver iron was not associated with the risk of HCC occurrence $(\mathrm{HR}=1.1[0.5-2.3]$ LogRank=0.7).

Liver iron score when considered as a continuous variable was associated in this cohort with male gender, hyperferritinemia, and Child-Pugh score (Table 3).

\section{HFE gene mutations and risk of $\mathrm{HCC}$}

\section{Patients with alcoholic cirrhosis}

Thirteen/162 patients (8.0\%) were carriers of the C282Y mutation (table 1). Among them $7 / 13(53.8 \%)$ developed HCC vs $33 / 149$ non carriers $(22.5 \%)($ Chi2 test $=0.01)$ According to Kaplan-Meier method (Figure 3), C282Y mutation carriage was found associated with HCC occurrence (first quartile time to occurrence of HCC: 50.0 vs 79.0 
months, $\mathrm{HR}=2.7$ [1.2-6.3] LogRank=0.01). In univariate analysis according to Cox's proportional hazards model, $\mathrm{C} 282 \mathrm{Y}$ mutation carriage was associated with the risk of HCC (2.7 [1.2-6.3], $\mathrm{p}=0.01)$ along with age, male gender, and liver iron score (Table 2). In multivariate analysis taking in account all these parameters, $\mathrm{C} 282 \mathrm{Y}$ mutation carriage remained an independent risk factor for HCC along with age and liver iron score (4.6 [1.811.5], $\mathrm{p}=0.001)$.

During follow-up, $3 / 13(23.0 \%)$ of the C282Y mutation carriers died vs $46 / 149$ $(30.8 \%)$ non carriers (Chi2 test $=0.5)$. $\mathrm{C} 282 \mathrm{Y}$ mutation carriage was not associated with the risk of death (first quartile time of survival: 64.0 vs 64.0 months, $H R=0.7$ [0.2-2.5] LogRank=0.1)

C282Y mutation carriers had higher liver iron scores $(3.6 \pm 3.8$ vs $1.9 \pm 2.8, p=0.05)$ (Table 3).

Fourty-four/162 patients $(27.1 \%)$ were carriers of the H63D mutation. This carriage was not associated neither with liver iron overload ( $1.9 \pm 2.9$ vs $1.8 \pm 3.1, p=0.8)$ nor with the risks of $\mathrm{HCC}(\mathrm{HR}=1.3[0.7-2.5] \operatorname{LogRank}=0.3)$ or death $(\mathrm{HR}=1.6[0.7-3.6] \operatorname{LogRank}=0.1)$.

\section{Patients with HCV-related cirrhosis}

Seventeen/139 patients (12.2\%) were carriers of the C282Y mutation (table 1). Among them 5/17 (29.4\%) developed HCC vs 58/122 non carriers (47.5\%) (Chi2 test $=0.1)$ According to Kaplan-Meier method (Figure 3), C282Y mutation carriage was not associated with the risk of HCC occurrence (first quartile time to occurrence of HCC: 60.0 vs 48.0 months, HR=0.2 [0.5-1.2], LogRank=0.1).

During follow-up, $3 / 17(17.6 \%)$ of the C282Y mutation carriers died vs $25 / 122$ (20.4\%) non carriers (Chi2 test $=0.7)$. C282Y mutation carriage was not associated with the 
risk of death (first quartile time of survival: 114.0 vs 112.0 months, $H R=0.7$ [0.2-2.24], LogRank=0.6).

Thirty-five/139 patients (25.1\%) were carriers of the H63D mutation. This carriage was not associated neither with liver iron overload $(0.8 \pm 1.6$ vs $0.9 \pm 2.0, p=0.6)$ nor with the risks of $\mathrm{HCC}(\mathrm{HR}=0.7$ [0.4-1.4] LogRank=0.4) or death $(\mathrm{HR}=0.9$ [0.5-1.6] LogRank=0.3).

Finally neither C282Y nor H63D mutations influenced SVR in this cohort (data not shown).

\section{Comparison of the two cohorts}

Patients with HCV-related cirrhosis were older, more often females, had a less severe liver dysfunction and lower liver iron scores than patients with alcoholic cirrhosis: mean iron score $0.9 \pm 1.9$ (ranging from 0 to 11 , median=0 $[\mathrm{Q} 1=0-\mathrm{Q} 3=1]$ ) versus mean iron score 2.0 \pm 3.0 (ranging from 0 to 14 , median $=0[\mathrm{Q} 1=0-\mathrm{Q} 3=3]$ ) respectively $(\mathrm{p}=0.0007)$. Similarly, the number of $\mathrm{HCV}$-infected patients with stainable liver iron (liver iron score $>0$ ) was lower compared with alcoholics ( $28.0 \%$ versus $45.6 \%, \mathrm{p}=0.006)$.

Patients with HCV-related cirrhosis had a higher incidence of HCC for a longer follow-up (first quartile time to occurrence of HCC: 50.0 vs 72.0 months, HR=1.51 [1.012.26], $\operatorname{LogRank}=0.04$ ), but this difference did not remain significant in multivariate analysis including age, gender and Child-Pugh score.

Although both cohorts were independent, we compared the influence of liver iron overload on the risk of HCC by calculating the likelihood ratio taking in account the results of multivariate analysis. Using this method, the likelihood ratio for patients with HCV-related cirrhosis was $0.22(\mathrm{p}=0.6)$ compared with $5.21(\mathrm{p}=0.02)$ in patients with alcoholic cirrhosis. 


\section{DISCUSSION}

By independently analyzing iron metabolism parameters in two distinct cohorts of cirrhotic patients according to the cause of their liver disease, our results suggest that liver iron overload and HFE gene mutations may not participate equally in alcohol- or HCVinduced hepatocarcinogenesis. In our study, patients with HCV-related cirrhosis had lower hepatic iron scores than patients with alcoholic cirrhosis even if older. As a possible consequence, this lower iron accumulation did not influence the risk of HCC occurrence or death in these patients and was not associated with the presence of HFE gene mutations. The mechanisms of iron accumulation in CHC are not clearly understood: several works reported a possible relationship with HFE gene mutations, ${ }^{16,17}$ while others as in our study did not. ${ }^{18 \text {, }}$ 19 These conflicting results suggest that other genetic or environmental factors may participate in hepatic iron accumulation; it has been suggested that the mild liver iron overload observed in the course of $\mathrm{CHC}$ could be a consequence of hepatocyte necrosis leading to release of ferritin and subsequent uptake by macrophages. ${ }^{20,21}$ Indeed, iron overload seems to be associated with increased histological activity and enhanced fibrosis ${ }^{20}$ ${ }^{21}$ and a recent study focused on liver iron accumulation in patients with $\mathrm{CHC}$ concluded that the observed mild iron overload in these patients may contribute to liver fibrosis progression but not aggravation towards end-stage liver disease. ${ }^{22}$ Finally, the lack of influence of HFE gene mutations on HCC occurrence in our work is consistent with all previous case-control studies conducted in HCV-related cirrhotic patients. ${ }^{11-13}$ Taken together, these reports suggest that moderate liver iron accumulation in the course of $\mathrm{CHC}$ is not clearly related to the presence of HFE gene mutations and does not lead to a higher incidence of HCC in patients with HCV-related cirrhosis, either because it is limited or because hepatocarcinogenesis in the course of this disease is not mainly related to oxidative stress but to an oncogenic although probably indirect role of the virus. Along with the assessment of 
clinical and biochemical risks factors for $\mathrm{HCC}$ occurrence in large cohorts of HCV-infected patients without cirrhosis, the influence of the virus itself on hepatocarcinogenesis needs further investigations.

Conversely to $\mathrm{HCV}$ infection, increased hepatic iron accumulation is a contributing factor to liver injury in the course of alcoholic liver disease; mechanisms by which ethanol leads to liver iron overload have been explored. ${ }^{23}$ If liver iron overload is a well-recognized carcinogen in experimental studies, clinical studies failed up to now to clearly assess its role as a risk factor for HCC, except in patients with haemochromatosis ${ }^{6}$ or patients with HCC developped on non-cirrhotic liver. ${ }^{24}$ The present work describes a strong association between this histological parameter and the risk of subsequent HCC occurrence in patients with alcoholic cirrhosis, either when considering liver iron overload as a continuous variable or in a binary coding. One of the major challenge for admitting a physiopathological role of liver iron deposition in hepatocarcinogenesis is the powerful relationship between hepatic iron overload, ageing and male gender which are also well-established epidemiological risk factors for HCC in cirrhotic patients. Thus, a multivariate analysis including these factors is required to demonstrate an independant role of hepatic iron overload: such an analysis was made possible in our study by the large number of events due to a long follow-up of our cohort. Additionally, the predictive value of $\mathrm{C} 282 \mathrm{Y}$ mutation provides a confirmation that liver iron is not the surrogate marker of other risk factors. Furthermore, the observed influence of liver iron on death in these patients (confirming data from Ganne-Carrie et al with the same optimal threshold value) ${ }^{14}$ suggests a possible underestimation of this carcinogenic effect as patients with high liver iron overload died early from liver failure before developing HCC.

The influence of the $\mathrm{C} 282 \mathrm{Y}$ mutation carriage on the risk of $\mathrm{HCC}$ as well as on hepatic iron overload is still debated. Some but not all case-control studies found a higher prevalence of this mutation in patients with HCC developped on alcoholic cirrhosis along 
with higher liver iron accumulation, ${ }^{10,11}$ as in the present work. As the prevalence of this mutation is low in the general population, all these studies, including ours, suffer from a lack of statistical power. Despite this limitation, our results display the influence of this mutation on the risk of $\mathrm{HCC}$ in alcoholic cirrhotic patients; furthermore, this association remains statistically significant in multivariate analysis taking in account age and gender. Although the association between the $\mathrm{C} 282 \mathrm{Y}$ mutation carriage with higher liver iron scores just reached statistical significance, we hypothesize that the observed influence of this mutation on hepatocarcinogenesis in alcoholic patients is related to hepatic iron overload. Still, HFE $\mathrm{C} 282 \mathrm{Y}$ mutation is not the exclusive factor explaining why some alcoholic patients develop hepatic iron overload; environmental factors such as the type of alcohol consumption or other nutritional parameters could be involved. As well, seeking for genetic factors other than HFE gene mutations influencing this accumulation is of major interest. Recent reports studying the influence of mitochondrial antioxidant enzymes polymorphisms displayed a possible role of the imbalance in antioxidant systems caused by alcohol consumption and differences in antioxidant enzymes activity in liver iron accumulation and HCC developpment, ${ }^{25,26}$ possibly through enhanced mitochondrial hydrogen peroxide production. These findings highlight the fact that hepatic iron accumulation could be also a consequence and not only a cause of enhanced oxidative stress in the course of alcoholic liver disease, establishing the basis of a vicious circle.

Our suggestion that liver iron overload on initial biopsy and C282Y mutation carriage may influence the outcome of alcoholic cirrhotic patients is consistent with previous studies conducted in patients with end-stage liver disease. Indeed, it has been shown that iron overload in patients undergoing liver transplantation was associated with an increased prevalence of HCC. ${ }^{27}$ Moreover, carriage of the $\mathrm{C} 282 \mathrm{Y}$ mutation, presumably by favoring iron overload, was also found associated with a poorer prognosis in patients undergoing 
resection for HCC. ${ }^{28}$ Our findings demonstrate that these parameters if evaluated at the time of diagnosis of alcoholic cirrhosis predict a poor outcome and that liver iron overload could be therefore a therapeutic target before the onset of end-stage liver disease.

Taken together, these results stress the need to prospectively assess HCC risk factors in well-defined cohorts of cirrhotic patients. Our data suggest that in patients with alcoholic cirrhosis, liver iron overload (whatever its cause) is a major risk factor of HCC occurrence. Prevention strategies aiming to lower liver iron load in selected patients might help to clarify its pathophysiological role. Trying to prevent HCC occurrence by iron depletion or chelation seems reasonable and should be evaluated in the future in alcoholic cirrhotic patients with liver iron overload and/or carriers of the C282Y mutation. 


\begin{tabular}{|c|c|c|c|}
\hline & $\begin{array}{l}\text { Patients with } \\
\text { alcoholic cirrhosis } \\
\quad(\mathbf{n}=162)\end{array}$ & $\begin{array}{c}\text { Patients with } \\
\text { HCV-related } \\
\text { cirrhosis } \\
(n=139) \\
\end{array}$ & $p$ \\
\hline Age (years) ${ }^{a}$ & $53.3 \pm 9.6$ & $59.2 \pm 13.0$ & $<0.0001$ \\
\hline Male gender $^{b}$ & $115(70.9)$ & $73(52.6)$ & $<0.0001$ \\
\hline $\begin{array}{l}\text { Alcohol consumption } \\
\text { (g/day) }^{\mathbf{a}}\end{array}$ & $112.3 \pm 30.6$ & $<20$ & - \\
\hline BMI $\left(\mathrm{kg} / \mathrm{m}^{2}\right)^{a}$ & $25.8 \pm 4.5$ & $26.9 \pm 6.8$ & 0.09 \\
\hline Diabetes $^{b}$ & $25(15.4)$ & $31(22.3)$ & 0.1 \\
\hline Child Pugh score $^{a}$ & $8.0 \pm 2.5$ & $5.2 \pm 1.0$ & $<0.0001$ \\
\hline $\begin{array}{l}\text { Prothrombin activity } \\
(\%)^{\mathrm{a}}\end{array}$ & $59.8 \pm 18.8$ & $85.3 \pm 14.8$ & $<0.0001$ \\
\hline Bilirubin $(\mathrm{mol} / \mathrm{L})^{a}$ & $69.3 \pm 90.1$ & $17.8 \pm 8.4$ & $<0.0001$ \\
\hline $\operatorname{Albumin}(g / L)^{a}$ & $34.8 \pm 7.0$ & $41.3 \pm 4.7$ & $<0.0001$ \\
\hline $\begin{array}{l}\text { Platelet count } \\
\left(10^{3} / \mathbf{m m}^{3}\right)^{a^{a}}\end{array}$ & $144.8 \pm 72.7$ & $140.0 \pm 59.4$ & 0.8 \\
\hline $\operatorname{AST}(\mathbf{U L N})^{a}$ & $2.3 \pm 1.5$ & $2.1 \pm 0.8$ & 0.8 \\
\hline $\operatorname{ALT}(\mathbf{U L N})^{a}$ & $1.3 \pm 0.8$ & $2.7 \pm 1.7$ & $<0.0001$ \\
\hline GGT (ULN) ${ }^{a}$ & $7.1 \pm 9.5$ & $2.0 \pm 1.1$ & $<0.0001$ \\
\hline HCV genotype $1^{b}$ & - & $109(78.4)$ & - \\
\hline Ferritin $(\mathrm{mg} / \mathrm{L})^{a}$ & $452.3 \pm 552.6$ & $290.2 \pm 288.9$ & 0.01 \\
\hline Liver iron score ${ }^{a}$ & $2.0 \pm 3.0$ & $0.9 \pm 1.9$ & 0.0007 \\
\hline$>0^{b}$ & $74(45.6)$ & $39(28.0)$ & 0.006 \\
\hline$>2^{b}$ & $52(32.0)$ & $22(15.8)$ & 0.0006 \\
\hline$>5^{b}$ & $22(13.5)$ & $6(4.3)$ & 0.006 \\
\hline C282Y mutation ${ }^{b}$ & $13(8.0)$ & $17(12.2)$ & 0.2 \\
\hline
\end{tabular}




\begin{tabular}{lccc} 
H63D mutation & b & $35(25.1)$ & 0.7 \\
\hline $\begin{array}{l}\text { Follow-up (months) } \\
\text { a }\end{array}$ & $66.1 \pm 45.1$ & $85.5 \pm 42.1$ & $<0.0001$ \\
$\begin{array}{l}\text { Anti-viral treatment } \\
\text { b }\end{array}$ & - & $80(57.5)$ & - \\
$\begin{array}{l}\text { Sustained virological } \\
\text { response }^{\text {b }}\end{array}$ & - & $32(23.0)$ & - \\
HCC $^{\text {b }}$ & $40(24.6)$ & & 0.0002 \\
Death $^{\text {b }}$ & $49(30.2)$ & $63(45.3)$ & 0.04 \\
HCC-related & 19 & $28(20.1)$ & \\
Liver-related & 30 & 25 & \\
Transplantation & 4 & 3 & \\
\hline
\end{tabular}

NOTE: aMean \pm SD. bNumber (percentage) of patients.

Table 1- Baseline characteristics and outcome of 162 patients with alcoholic cirrhosis and 139 patients with HCV-related cirrhosis. 
Cox univariate analysis

Cox multivariate analysis
(including liver iron score as a continuous variable)

\section{Cox multivariate analysis (including liver iron score with threshold $\geq 2$ )}

\section{Age}

$$
1.084[1.048-1.121]
$$$$
\mathrm{p}<0.0001
$$

$$
\begin{gathered}
1.082[1.042-1.124] \\
\mathrm{p}<0.0001
\end{gathered}
$$

$$
3.1[1.1-8.8]
$$$$
\mathrm{p}=0.03
$$

Liver iron score (continuous

variable)

Liver iron score (Threshold $\geq 2$ )

$$
1.2[1.1-1.3]
$$$$
\mathrm{p}<0.0001
$$

$$
4.1[2.1-7.3]
$$$$
\mathrm{p}<0.0001
$$

$$
\begin{gathered}
2.7[1.2-6.3] \\
p=0.01
\end{gathered}
$$

$1.086[1.046-1.128]$
$\mathrm{p}<0.0001$

$$
2.8[0.9-6.7]
$$$$
\mathrm{p}=0.08
$$

$$
1.1[1.0-1.2]
$$$$
\mathrm{p}=0.003
$$

$$
-
$$

$$
\begin{gathered}
2.8[1.4-5.4] \\
p=0.002
\end{gathered}
$$

\section{$4.6[1.8-11.5]$}

$\mathrm{p}=0.001$

$$
\begin{gathered}
4.7[1.9-11.7] \\
p=0.0007
\end{gathered}
$$

Cox univariate analysis $1.026[1.003-1.049]$
$\mathrm{p}=0.02$

$$
\begin{gathered}
1.7[1.0-2.8] \\
\mathrm{p}=0.03
\end{gathered}
$$$$
\mathrm{p}=0.03
$$

$$
\begin{gathered}
1.0[0.9-1.2] \\
\mathrm{p}=0.3
\end{gathered}
$$

$$
1.0[0.5-1.8]
$$$$
\mathrm{p}=0.8
$$$$
0.5[0.2-1.2]
$$$$
\mathrm{p}=0.1
$$

Cox multivariate analysis (including liver iron score as a continuous variable)

$1.019[0.987-1.079]$
$p=0.2$

$$
\begin{gathered}
1.6[1.0-2.7] \\
p=0.04 \\
\begin{array}{c}
0.9[0.7-1.3] \\
p=0.8
\end{array} \\
- \\
0.6[0.3-1.4] \\
p=0.2 \\
0.3[0.1-0.5] \\
p<0.0001 \\
0.6[0.3-1.4] \\
p=0.6
\end{gathered}
$$

$\begin{array}{cc}0.2[0.1-0.4] & 0.3[0.1-0.5] \\ \mathrm{p}<0.0001 & \mathrm{p}<0.0001\end{array}$

$0.4[0.2-0.9] \quad 0.6[0.3-1.4]$

Table 2- Clinical and biochemical features associated with the risk of HCC occurrence in patients with alcoholic or HCV-related cirrhosis according to Cox's proportional hazards model. 
Age (Correlation)

$\mathrm{r}=0.26(\mathrm{p}=0.0008)$

$\mathrm{r}=0.09(\mathrm{p}=0.2)$

Male gender (males vs

females)

$2.4 \pm 3.2$ vs $1.4 \pm 1.9(\mathrm{p}=0.02) \quad 1.4 \pm 2.2$ vs $0.8 \pm 1.7(\mathrm{p}=0.008)$

Child-Pugh score

$\mathrm{r}=0.9(\mathrm{p}=0.08)$

$\mathrm{r}=0.18(\mathrm{p}=0.03)$

(Correlation)

Ferritin (Correlation)

$r=0.22(p=0.006)$

$\mathrm{r}=0.30(\mathrm{p}=0.006)$

C282Y mutation (carriers

$3.6 \pm 3.8$ vs $1.9 \pm 2.8(\mathrm{p}=0.05)$

$1.1 \pm 1.9$ vs $0.9 \pm 1.9(\mathrm{p}=0.2)$ vs non carriers)

Table 3- Clinical and biochemical features associated with liver iron overload in patients with alcoholic or HCV-related cirrhosis 


\section{REFERENCES}

1. Sangiovanni A, Del Ninno E, Fasani P, De Fazio C, Ronchi G, Romeo R, Morabito A, De Franchis R, Colombo M. Increased survival of cirrhotic patients with a hepatocellular carcinoma detected during surveillance. Gastroenterology 2004;126:1005-14.

2. Llovet JM, Bruix J. Early diagnosis and treatment of hepatocellular carcinoma. Baillieres Best Pract Res Clin Gastroenterol 2000;14:991-1008.

3. Llovet JM, Fuster J, Bruix J. The Barcelona approach: diagnosis, staging, and treatment of hepatocellular carcinoma. Liver Transpl 2004;10:S1 15-20.

4. Lodato F, Mazzella G, Festi D, Azzaroli F, Colecchia A, Roda E. Hepatocellular carcinoma prevention: A worldwide emergence between the opulence of developed countries and the economic constraints of developing nations. World J Gastroenterol 2006;12:7239-49.

5. Feder JN, Gnirke A, Thomas W, Tsuchihashi Z, Ruddy DA, Basava A, Dormishian F, Domingo R, Jr., Ellis MC, Fullan A, Hinton LM, Jones NL, Kimmel BE, Kronmal GS, Lauer P, Lee VK, Loeb DB, Mapa FA, McClelland E, Meyer NC, Mintier GA, Moeller N, Moore T, Morikang E, Prass CE, Quintana L, Starnes SM, Schatzman RC, Brunke KJ, Drayna DT, Risch NJ, Bacon BR, Wolff RK. A novel MHC class I-like gene is mutated in patients with hereditary haemochromatosis. Nat Genet 1996;13:399-408.

6. Fargion S, Mandelli C, Piperno A, Cesana B, Fracanzani AL, Fraquelli M, Bianchi PA, Fiorelli G, Conte D. Survival and prognostic factors in 212 Italian patients with genetic hemochromatosis. Hepatology 1992;15:655-9. 
7. Kew MD. Pathogenesis of hepatocellular carcinoma in hereditary hemochromatosis: occurrence in noncirrhotic patients. Hepatology 1990;11:1086-7.

8. Deugnier Y. Iron and liver cancer. Alcohol 2003;30:145-50.

9. Kowdley KV. Iron, hemochromatosis, and hepatocellular carcinoma. Gastroenterology 2004;127:S79-86.

10. Hellerbrand C, Poppl A, Hartmann A, Scholmerich J, Lock G. HFE C282Y heterozygosity in hepatocellular carcinoma: evidence for an increased prevalence. Clin Gastroenterol Hepatol 2003;1:279-84.

11. Lauret E, Rodriguez M, Gonzalez S, Linares A, Lopez-Vazquez A, Martinez-Borra J, Rodrigo L, Lopez-Larrea C. HFE gene mutations in alcoholic and virus-related cirrhotic patients with hepatocellular carcinoma. Am J Gastroenterol 2002;97:1016-21.

12. Boige V, Castera L, de Roux N, Ganne-Carrie N, Ducot B, Pelletier G, Beaugrand M, Buffet C. Lack of association between HFE gene mutations and hepatocellular carcinoma in patients with cirrhosis. Gut 2003;52:1178-81.

13. Cauza E, Peck-Radosavljevic M, Ulrich-Pur H, Datz C, Gschwantler M, SchonigerHekele M, Hackl F, Polli C, Rasoul-Rockenschaub S, Muller C, Wrba F, Gangl A, Ferenci P. Mutations of the HFE gene in patients with hepatocellular carcinoma. Am J Gastroenterol 2003;98:442-7.

14. Ganne-Carrie N, Christidis C, Chastang C, Ziol M, Chapel F, Imbert-Bismut F, Trinchet JC, Guettier C, Beaugrand M. Liver iron is predictive of death in alcoholic cirrhosis: a multivariate study of 229 consecutive patients with alcoholic and/or hepatitis C virus cirrhosis: a prospective follow up study. Gut 2000;46:277-82.

15. de Kok JB, Wiegerinck ET, Giesendorf BA, Swinkels DW. Rapid genotyping of single nucleotide polymorphisms using novel minor groove binding DNA oligonucleotides (MGB probes). Hum Mutat 2002;19:554-9. 
16. Kazemi-Shirazi L, Datz C, Maier-Dobersberger T, Kaserer K, Hackl F, Polli C, Steindl PE, Penner E, Ferenci P. The relation of iron status and hemochromatosis gene mutations in patients with chronic hepatitis C. Gastroenterology 1999;116:127-34.

17. Piperno A, Vergani A, Malosio I, Parma L, Fossati L, Ricci A, Bovo G, Boari G, Mancia G. Hepatic iron overload in patients with chronic viral hepatitis: role of HFE gene mutations. Hepatology 1998;28:1105-9.

18. Hohler T, Leininger S, Kohler HH, Schirmacher P, Galle PR. Heterozygosity for the hemochromatosis gene in liver diseases--prevalence and effects on liver histology. Liver 2000;20:482-6.

19. Thorburn D, Curry G, Spooner R, Spence E, Oien K, Halls D, Fox R, McCruden EA, MacSween RN, Mills PR. The role of iron and haemochromatosis gene mutations in the progression of liver disease in chronic hepatitis C. Gut 2002;50:248-52.

20. Boucher E, Bourienne A, Adams P, Turlin B, Brissot P, Deugnier Y. Liver iron concentration and distribution in chronic hepatitis $\mathrm{C}$ before and after interferon treatment. Gut 1997;41:115-20.

21. Hezode C, Cazeneuve C, Coue O, Roudot-Thoraval F, Lonjon I, Bastie A, Duvoux C, Pawlotsky JM, Zafrani ES, Amselem S, Dhumeaux D. Liver iron accumulation in patients with chronic active hepatitis $\mathrm{C}$ : prevalence and role of hemochromatosis gene mutations and relationship with hepatic histological lesions. J Hepatol 1999;31:97984.

22. Tung BY, Emond MJ, Bronner MP, Raaka SD, Cotler SJ, Kowdley KV. Hepatitis C, iron status, and disease severity: relationship with HFE mutations. Gastroenterology $2003 ; 124: 318-26$.

23. Kohgo Y, Ohtake T, Ikuta K, Suzuki Y, Hosoki Y, Saito H, Kato J. Iron accumulation in alcoholic liver diseases. Alcohol Clin Exp Res 2005;29:189S-93 S. 
24. Blanc JF, De Ledinghen V, Bernard PH, de Verneuil H, Winnock M, Le Bail B, Carles J, Saric J, Balabaud C, Bioulac-Sage P. Increased incidence of HFE C282Y mutations in patients with iron overload and hepatocellular carcinoma developed in non-cirrhotic liver. J Hepatol 2000;32:805-11.

25. Sutton A, Nahon P, Pessayre D, Rufat P, Poire A, Ziol M, Vidaud D, Barget N, Ganne-Carrie N, Charnaux N, Trinchet JC, Gattegno L, Beaugrand M. Genetic polymorphisms in antioxidant enzymes modulate hepatic iron accumulation and hepatocellular carcinoma development in patients with alcohol-induced cirrhosis. Cancer Res 2006;66:2844-52.

26. Nahon P, Sutton A, Pessayre D, Rufat P, Degoul F, Ganne-Carrie N, Ziol M, Charnaux N, N'Kontchou G, Trinchet JC, Gattegno L, Beaugrand M. Genetic dimorphism in superoxide dismutase and susceptibility to alcoholic cirrhosis, hepatocellular carcinoma, and death. Clin Gastroenterol Hepatol 2005;3:292-8.

27. Kowdley KV, Hassanein T, Kaur S, Farrell FJ, Van Thiel DH, Keeffe EB, Sorrell MF, Bacon BR, Weber FL, Jr., Tavill AS. Primary liver cancer and survival in patients undergoing liver transplantation for hemochromatosis. Liver Transpl Surg 1995;1:23741.

28. Pirisi M, Toniutto P, Uzzau A, Fabris C, Avellini C, Scott C, Apollonio L, Beltrami CA, Bresadola F. Carriage of HFE mutations and outcome of surgical resection for hepatocellular carcinoma in cirrhotic patients. Cancer 2000;89:297-302. 


\section{FIGURE LEGENDS}

Figure 1- Influence of stainable liver iron on the risk of $\mathrm{HCC}$ occurrence in patients with alcoholic or HCV-related cirrhosis according to Kaplan-Meier method.

Figure 1a- 162 patients with alcoholic cirrhosis (first quartile time to occurrence: 54.0 months vs 180.0 months, $\mathrm{HR}=3.3[1.6-6.7], \operatorname{LogRank}=0.0006)$.

Figure 1b- 139 patients with HCV-related cirrhosis (first quartile time to occurrence: 48.0 months vs 50.0 months, $\mathrm{HR}=0.9$ [0.5-1.7], LogRank=0.9)

Figure 2- Influence of liver iron score $\geq 2$ on the risk of $\mathrm{HCC}$ occurrence in patients with alcoholic or HCV-related cirrhosis according to Kaplan-Meier method.

Figure 2a-162 patients with alcoholic cirrhosis (first quartile time to occurrence: 49.0 months vs 180.0 months, $\mathrm{HR}=4.2$ [2.1-8.5], LogRank<0.0001).

Figure 2b- 139 patients with HCV-related cirrhosis (first quartile time to occurrence: 48.0 months vs 55.0 months, $\mathrm{HR}=1.1[0.5-2.3]$, LogRank=0.7)

Figure 3- $\mathrm{C282}$ Y mutation carriage and risk of $\mathrm{HCC}$ occurrence according to KaplanMeier method.

Figure 3a- 162 patients with alcoholic cirrhosis (first quartile time to occurrence of HCC: 50.0 vs 79.0 months, $\mathrm{HR}=2.7$ [1.2-6.3], LogRank=0.01).

Figure 3b- 139 patients with HCV-related cirrhosis (first quartile time to occurrence of HCC: 60.0 vs 48.0 months, $H R=0.2$ [0.5-1.2], LogRank=0.1). 
Nahon et al 